\title{
CROSSING BOUNDARIES: DEVELOPING TRANSDISCIPLINARY SKILLS IN ENGINEERING EDUCATION
}

\author{
Tanya Tan, Susan Nesbit*, Naoko Ellis, Peter Ostafichuk \\ Faculty of Applied Science, University of British Columbia \\ Corresponding Author: nesbit@civil.ubc.ca
}

\begin{abstract}
Transdisciplinary engineering curricula prepare future engineers with a holistic understanding of complex real-world problems, and the ability to tackle these problems with knowledge and skills in both engineering and non-engineering areas. What are transdisciplinary skills in the engineering education context? What learning activities can we design and implement to develop students' transdisciplinary skills in the first-year engineering program? How can we assess transdisciplinary skills and evaluate the instructional effectiveness of these learning activities?

The current study is an initial attempt to explore these questions. We introduce a conceptual framework of using systems thinking, empathy and metacognition as proxy indicators of transdisciplinary skills, and present the learning activities we have designed to develop student competencies in these areas. In addition, we propose an evaluation approach that includes a survey instrument and formative learning assessment, with which we investigate the relationships among empathy, systems thinking, and metacognitive skills in the context of engineering education.
\end{abstract}

Keywords: first-year engineering, sustainability, transdisciplinarity, metacognition, empathy, systems thinking

\section{INTRODUCTION}

While transdisciplinarity is employed to address complex and ill-structured problems relating to sociotechnical concerns informed by engineering expertise (e.g. water scarcity, lack of housing, dwindling biodiversity, poverty, and climate change), some transdisciplinary skills are not currently learned by Canadian engineering students, and how to cultivate and assess such skills remain under-investigated [1], [2].

The present study aims to strengthen the theoretical and empirical foundations for transdisciplinary engineering curricula by exploring the following research questions:

(i) How can transdisciplinary skills be assessed in engineering education, using metacognition, empathy and systems thinking as proxy indicators?

(ii) Are empathy, systems thinking, and metacognitive skills correlated in the context of engineering education?

This paper describes systems thinking, empathy, and metacognition learning activities we have designed, and presents a test and analysis of the survey instrument deployed to gauge the influence of the learning activities on student knowledge and attitudes. We plan to deploy the learning activities in the 2018-2019 academic year, using the survey instrument, as well as structured interviews and formal learning assessments, to measure the instructional effectiveness of the learning activities, as they relate to the development of transdisciplinary skills.

\section{METHODS}

Our goal is to design and implement learning activities to support systems thinking, empathy, and metacognition in two consecutive first-year engineering courses, APSC 100 and APSC 101, each of which enrolls approximately 800 students at the University of British Columbia. The two courses are design-focused and built on a flippedclassroom format with two fifty-minute lectures and one two-hour studio session each week. Approximately sixty students are assigned to each studio section. To evaluate the instructional effectiveness, we collect formative assessment scores and administer a survey instrument at the beginning and end of the first-year engineering program. In particular, the survey measures knowledge of cognition [3] (17 true/false questions), the affective aspect of systems thinking [4] (11 five-point Likert scale items), and the perspective-taking aspect of empathy [5] (7 fivepoint Likert scale items) (Appendix: Transdisciplinary Skills Survey Instrument).

The Metacognitive Awareness Inventory (MAI) is a widely used survey instrument that measures the levels of metacognitive knowledge and regulation [3]. The knowledge of cognition consists of three sub-components, declarative knowledge, procedural knowledge and conditional knowledge. Specifically, declarative knowledge describes learners' knowledge about their abilities and their knowledge of the learning context; 
procedural knowledge is the knowledge of how to apply appropriate strategies; conditional knowledge refers to the knowledge of when and why to use strategies under certain circumstances. Regulation of cognition includes planning, monitoring, adaptation, and evaluation of cognitive activities. The learning activities that we have designed are more relevant to knowledge of cognition, yet not directly involving planning and evaluation of cognitive activities in a sufficiently long period of time to change students' behaviour. Our survey, therefore, retains only the cognition of knowledge component of MAI, which is formatted as true/false questions to shorten survey completion time.

The cognitive aspect of systems thinking can be interpreted and assessed with course assignments (i.e., causal loop diagrams described in the following section); whereas, the affective domain of systems thinking which deals with emotions and beliefs, is often neglected. To fill in the gap, Camelia et al. [4] developed and validated a survey instrument that measures the affective aspect of systems thinking in the context engineering education. We modified and adopted three subscales from the original survey, namely, managerial skills and holistic thinking (3 items), students' valuation of teamwork (4 items), and students' valuation of understanding relationships (4 items).

The Interpersonal Reactivity Index (IRI) is a widely used self-report questionnaire that measures four dimensions of dispositional empathy: empathic concern (tendency to have other-oriented feelings of concern of sympathy), perspective taking (tendency to imagine how another is thinking or feeling), fantasy (empathy for fictional characters), and personal distress (self-oriented feelings as a result of tense interpersonal situations). Among the four subscales, the perspective taking subscale is the most relevant to engineering education. The importance of perspective taking lies in understanding and accommodating to the needs of multiple stakeholders, especially those from other cultural and ethnic backgrounds [6].

Quantitative survey instrument is widely used in engineering education research to obtain large-scale opinions, attitudes, and self-perceived abilities so that researchers can make objective inferences through statistical analysis [7]. It is suitable for the present study because of the large enrollment courses in the first year engineering program as well as the deductive nature of the study [7]. However, quantitative studies lack in rich and in-depth detail of the learning process thus cannot directly answer why or how questions. Therefore, a mixed-method approach might be considered in the future to include both quantitative (survey instrument) and qualitative (semi-structured interview) data to explore how students develop their metacognition, empathy and systems thinking skills.

\section{RESULTS AND DISCUSSION}

The results of the current research include 1) a discussion of what constitutes transdisciplinary skills in engineering education; 2) a description and analysis of an evaluation approach of transdisciplinary skills; and 3) insights about the pedagogical practice of systems thinking, empathy and metacognition in first year engineering curricula. The present study extends the preliminary work [8] and further explores the pedagogical development and assessment of transdisciplinary skills.

\subsection{Transdisciplinary Skills in Engineering Education}

In this study, we propose to use systems thinking, empathy, and metacognition as proxy indicators of transdisciplinary skills. Transdisciplinarity can be characterized by the ability to think in a complex and interlinked manner [9], to reflect on knowledge integration [10], and to demonstrate interpersonal competencies such as empathy and open-mindedness [10]-[12].

Systems thinking enables dynamic assessments of the interrelationships among various knowledge domains and the process to construct an integrative system [4], [13]; and is considered a core competency to manage complex sustainability problems [14]-[16]. Skilled systems thinkers are able to establish an overarching framework across disciplines, which is a key component in transdisciplinarity. Systems thinking connects the theoretical and practical domains in engineering and allows engineers to approach a multi-level engineering problem holistically. For instance, systems thinking affords engineers the ability to assess, understand and accommodate the needs of stakeholders with a balanced design solution which are ultimately translated into the characteristics of the engineering design.

Moreover, empathy is essential to acknowledge and respect disciplinary differences and to effectively collaborate with individuals from diverse cultural backgrounds [6]. Empathy has been increasingly recognized as a core skill in engineering education [11] and professional practices [17]. Particularly, empathic perspective-taking is relevant to engineers because it enables deep understanding and genuine care for the needs and concerns of stakeholders who might be affected by the consequences of engineering solutions. Empathic perspective-taking hence facilitates ethical decisionmaking [18] and human-centred engineering design [19].

Metacognition also plays a significant role in transdisciplinary interactions by enabling individuals to monitor, reflect on, and adapt learning processes in a multidimensional context [20]. Vos \& De Graaff [21] claimed that the theoretical foundation of active learning in engineering (e.g. project-based learning) is the development of metacognition. Chowdhury [22] also 
exemplified how the development metacognition can be embedded in a power engineering course using reflective writing assignment, self-assessment and team project, where students were engaged in metacognitive behaviours such as identifying tasks, planning, monitoring progress, evaluation and adjustment of strategies.

Cognitive aptitude was found to suppress the ability to respond empathically at the neurological level [23], which was also observed in a longitudinal study where empathic competencies declined over the course of engineering education [24]. However, explicit instruction in empathic thought process can counteract the adverse effect of cognitive development [11], which eventually results in a positive relationship between cognitive aptitude and empathy. Therefore, we wonder whether metacognition, empathy and systems thinking are intertwined in the learning processes. Metacognition is known to facilitate cognitive processes (e.g. systems thinking) [25] and can support students' empathetic responses by eliciting awareness of the diversity in human cognition and emotions. Hence, we hypothesize that metacognition is positively correlated with systems thinking and empathy.

\subsection{Preliminary Data Analysis}

In September 2017, all APSC 100 students were invited to participate in the transdisciplinary survey online prior to attending their first studio. They were informed that their responses were completely anonymous and would not impact their course grades. A total of 684 valid responses were collected with the Cronbach's alpha = .767, which was above the acceptable level of .7. However, the following three survey items showed extremely low item-total coefficients.

Q1: I prefer to deal with big picture and systems aspects rather than technical details.

Q24: I learn best when I know something about the topic.

Q36 I learn more when I am interested in the topic.

We will determine whether to remove these items after we receive our post-course survey results in March 2018. Further, according to these pre-studio survey results, the metacognition score was positively correlated with both systems thinking score $(r=.307, p<.001)$ and empathy score $(r=.161, p<.001)$ at the .05 significance level. The correlation between systems thinking and empathy scores were also statistically significant $(r=.243, p<.001)$.

The results are consistent with our original hypotheses. As stated in 3.1, metacognition facilitates cognitive processes such as systems thinking - students who are more aware of their knowledge and thinking process, tend to identify the knowledge domains and the interconnections more easily. Further, the positive correlation between empathy and metacognition is also expected. Empathy can be categorized into emotional empathy and metacognitive empathy [26]. Emotional empathy is one's unconscious resonant response when he/she sees others' emotions [27] while perspectivetaking is a metacognitive empathy, representing a mindful and conscious effort to seek understanding of others' perspectives and feelings without direct interpersonal interactions. It is thus plausible to observe that, students who held higher levels of metacognitive awareness, also tended to have stronger abilities to take others' perspectives [28]. In the context of a learning intervention, if students are metacognitively aware of their feelings, they gradually learn to anticipate the life events that lead to those feelings that could have happened to others. Reciprocally, once people empathize with others, they are also likely to be more aware of their own feelings [29].

It should be noted that the survey instrument measures the affective aspect of systems thinking - more specifically the students' perceptions of managerial skills and holistic thinking (example item, "I prefer leading teams rather than concentrating on my technical job"), understanding of relationships (example item, "When I contribute to a group project, I work hard to maintain communication with others involved") and teamwork (example item "When I contribute to a group project, I prefer to test the available alternative solutions and then recommend the best choice rather than to let others choose the preferred alternative."). In other words, the survey does not measure the ability to think systematically which, instead, will be assessed by the formative assignment during the learning activities, as described in the following section.

\subsection{Systems Thinking Learning Activity}

One of the main features of systems thinking is the recognition of the interdependence within the systems. Causal loop diagram visually reveals the interrelationships among a number of variables in complex domains in a simplified fashion. It has been used as an assessment tool to promote systems thinking in transdisciplinary problem-solving [30], [31]. The systems thinking learning activity, which takes place during a 2hour studio session, aims to build on each student's definition of a complex system such that, by the end of the activity, s/he can create a simple causal loop diagram (CLD) describing a complex, ill-structured, sustainability problem. Creating and using the diagram helps students to both identify possible interventions to address the sustainability problem, and envision possible implications of decision options. Before coming to the studio, students are introduced to sustainability, complex systems, and the basics of causal loop diagram construction.

During the studio, the instructor first walks student teams through the creation of a very simple causal loop diagram, starting with the consideration of a simple wellstructured engineering problem and ending with a causal loop diagram for the engineering problem which, the 
students soon discover, is more complex than they initially assume. After a class discussion on complexity and ill-structured problems, student teams are asked to consider why the decision to build a power plant in British Columbia is contentious. The class briefly discuss questions related to the problem (e.g., "What are the current sources of energy in B.C.?", "What might impact the demand for energy in B.C. over the next 30 years?"). Then the class generates a list of possible variables. Each team then sketches a causal loop diagram describing relationships between the variables. Once completed, each team posts its CLD on the classroom walls and the students do a gallery walk. The class discusses similarities and differences between the CLDs and, finally, teams grapple with how these CLDs might help identify decision criteria regarding the decision of choosing a power plant option for British Columbia (including the "do nothing" option).

Feedback to the instructor of student performance is provided during the studio session described above via inspection of the CLDs that teams produce and the discussions that occur during the studio. In a subsequent studio session, each student team gives an oral presentation of their recommendation for the power plant decision. The presentation assessment rubric includes a criterion requiring demonstration of systems thinking. A final examination question provides an individual summative assessment of systems thinking. This question varies from year to year and may ask students to complete a CLD, or otherwise illustrate their understanding of complex systems that relate to engineering decision making.

\subsection{Empathy Learning Activity}

In the engineering context, empathy may not be explicitly stated and applied, but rather intrinsic in the engineering profession as contributing to the betterment of society [32]. However, the discourse on empathy is growing, not just in the global context, but also in the engineering community through the recognition of the need for effective communication, ethical reasoning and user-centred design [33]. In particular, the user-centred design requires understanding the needs of a user, and perspective taking, which empathy plays a key role. Thus, it is not surprising that a number of studies have explored using design as means to foster empathy in engineering students [34], [35].

The proposed activities aim at cultivating awareness of the significance of empathy on human-centred design through authentic listening and empathy mapping. During the first term, students are introduced to general design and its process. The first activity aims at students exercising their authentic listening skills. In pairs, they will sit facing each other and each has 10 minutes to talk while the other listens in complete silence. The role is reversed and repeated. In the first term, the concept of stakeholders and their influence is examined through a case study concerning a fictitious hydropower dam to be built. In the studio, an activity is run where some students assume different stakeholder identities, and participate in a role-play discussion, while other students observe and discuss the perspectives and goals of different stakeholders. In the second term, students are challenged with designing a system to solve a water stress problem in a remote community. Through this process, students watch recorded interviews of local people from Van Anda community who talk about their issues of water supply. Students in teams then draw an empathy map on what the residents saw, did, thought and felt during the interview. Further discussions take place with studio instructors and engineers who have been involved in the community water project. One possible assessment on empathy may involve the interpersonal reactivity index (IRI) [5].

\subsection{Metacognition Learning Activity}

It is well established in the literature that metacognitive awareness is positively correlated to favourable course outcomes [36]-[38], and that introducing students to metacognition and related concepts leads to improved learning outcomes [39], [40]. Importantly, significant benefits have been observed with minimal interventions consisting of simply introducing concepts of metacognition [41].

With this in mind, we have begun development of a series of new course activities for APSC 100 in 2018 to introduce and develop various concepts related to metacognition. As described previously, the course is structured in a flipped classroom format, and each week begins with a series of online screencasts (videos with quizzes and other interactive features) completed before Mondays at 8:00 am. The materials related to metacognition is delivered in a similar manner, with short (4-5 minute) videos followed by quiz questions, reflections, and other interactive learning activities. These materials are mandatory, carrying a small mark weight (by virtue of scores on the embedded quizzes and other activities, totalling less than $2 \%$ of overall course grade). In total, five videos are planned, released one per week over five weeks near the start of the first term:

- Learning myths: dispelling the fixed mindset and other common myths about learning [42]

- A healthy brain: the science of sleep, diet, exercise, and lifestyle on learning [43]

- How learning works: how the brain encodes, stores, and recalls information, and how to do this better [36], [37], [43]

- Metacognition: what is it and why you should care [44] 
- Effective learning techniques: putting all these ideas into practice [45]

Part of the reason for this approach is that the screencast format is familiar to the students, and ensures the metacognition topics are not automatically differentiated (and potentially devalued) by students compared to other "technical" course content. The use of screencasts will also create a resource that students can refer back to over their entire first year. Lastly, making this a multi-week intervention will allow opportunities for applying (and explicitly highlighting) concepts such as distributed practice, elaboration, reflection, and transference.

The embedded quizzes and learning activities in the screencasts are expected to yield additional research data in two forms. First, we will be able to assess the degree of student understanding of basic metacognition concepts presented. Second, we are planning to embed various interactive questionnaire and survey instruments on effective learning strategies, growth mindset, and learning myths. These latter tools are primarily being added for students' benefit to help them gauge their own beliefs and preferences, but they will also allow us, with student consent, to collect this data for consideration in the study.

\section{CONCLUSION AND NEXT STEPS}

Transdisciplinary skills are vital to addressing the sustainability challenges our society face in the $21^{\text {st }}$ century. The demands of industry are also shifting from disciplinary specialists to graduates with transdisciplinary competencies to tackle complex real-world problems. It is thus increasingly important to provide learning opportunities for first-year students to integrate knowledge across disciplinary boundaries.

This study has outlined a conceptual framework for developing and evaluating students' transdisciplinary skills which encompass systems thinking, metacognition and empathy. The preliminary results suggest that the survey instrument is applicable to the engineering context with a reasonably high reliability. In addition, the outcomes of the pre-studio survey indicate the positive correlations among metacognition, systems thinking, and empathy scores, and support our initial hypotheses that metacognition, systems thinking and empathy are related constructs.

Our future investigation will focus on refining the aforementioned learning activities and implementing some or all of them in the academic year of 2018/2019. We will again collect pre- and post-course survey data and compare the result with that collected this year. We may also consider using the mixed method: triangulating the results from the survey instrument with, those from student and faculty interviews to further understand 1) students' and faculty's perceptions of transdisciplinary skills 2) how transdisciplinary skills have developed through the designed activities.

\section{Acknowledgements}

We thank APSC 100 and APSC 101 students who volunteered their time participating in this study.

\section{References}

[1] A. Ertas, T. Maxwell, V. P. Rainey, and M. M. Tanik, "Transformation of higher education: the transdisciplinary approach in engineering," IEEE Transactions on Education, vol. 46, no. 2, pp. 289295, May 2003.

[2] A. Di Giulio and R. Defila, "Enabling university educators to equip students with inter- and transdisciplinary competencies," International Journal of Sustainability in Higher Education, vol. 18, no. 5, pp. 630-647, Jul. 2017.

[3] G. Schraw and R. S. Dennison, "Assessing metacognitive awareness," Contemporary Educational Psychology, vol. 19, no. 4, pp. 460-475, Oct. 1994.

[4] F. Camelia, T. L. J. Ferris, and D. H. Cropley, "Development and Initial Validation of an Instrument to Measure Students' Learning About Systems Thinking: The Affective Domain," IEEE Systems Journal, vol. 12, no. 1, pp. 115-124, Mar. 2018.

[5] M. H. Davis, "Measuring individual differences in empathy: Evidence for a multidimensional approach.," Journal of Personality and Social Psychology, vol. 44, no. 1, pp. 113-126, 1983.

[6] C. Rasoal, H. Danielsson, and T. Jungert, "Empathy among students in engineering programmes," European Journal of Engineering Education, vol. 37, no. 5, pp. 427-435, Oct. 2012.

[7] M. Borrego, E. P. Douglas, and C. T. Amelink, "Quantitative, qualitative, and mixed research methods in engineering education," Journal of Engineering Education, vol. 98, no. 1, pp. 53-66, Jan. 2009.

[8] S. Nesbit, N. Ellis, and P. Ostafichuk, "Working with 'Others': Developing Sustainability Skills in the First Year Engineering Classroom," in Conference Proceedings of CEEA, 2017.

[9] Bers and J. H. Bernstein, "Transdisciplinarity: A review of its origins, development, and current issues," Journal of Research Practice, vol. 11, no. 1, p. 1, Jul. 2015.

[10] T. Augsburg, "Becoming transdisciplinary: The 
emergence of the transdisciplinary individual," World Futures, vol. 70, no. 3-4, pp. 233-247, May 2014.

[11] J. Walther, S. E. Miller, and N. W. Sochacka, "A Model of Empathy in Engineering as a Core Skill, Practice Orientation, and Professional Way of Being," Journal of Engineering Education, vol. 106, no. 1, pp. 123-148, Jan. 2017.

[12] J. Lönngren, M. Svanström, A. Ingerman, and J. Holmberg, "Dealing with the multidimensionality of sustainability through the use of multiple perspectives - a theoretical framework," European Journal of Engineering Education, vol. 41, no. 3, pp. 342-352, May 2016.

[13] W. Hung, "Enhancing systems-thinking skills with modelling," British Journal of Educational Technology, vol. 39, no. 6, pp. 1099-1120, Nov. 2008.

[14] A. Dale and L. Newman, "Sustainable development, education and literacy," International Journal of Sustainability in Higher Education, vol. 6, no. 4, pp. 351-362, Dec. 2005.

[15] S. M. Remington-Doucette, K. Y. Hiller Connell, C. M. Armstrong, and S. L. Musgrove, "Assessing sustainability education in a transdisciplinary undergraduate course focused on real-world problem solving," International Journal of Sustainability in Higher Education, vol. 14, no. 4, pp. 404-433, Sep. 2013.

[16] A. Wiek et al., "Operationalising competencies in higher education for sustainable development," Handbook of higher education for sustainable development. Routledge, pp. 241-260, 2015.

[17] J. L. Hess, J. Strobel, R. (Celia) Pan, and C. A. Wachter Morris, "Insights from industry: a quantitative analysis of engineers' perceptions of empathy and care within their practice," European Journal of Engineering Education, vol. 42, no. 6, pp. 1128-1153, Nov. 2017.

[18] J. L. Hess, J. Beever, J. Strobel, and A. O. Brightman, "Empathic Perspective-Taking and Ethical DecisionMaking in Engineering Ethics Education," Springer, Cham, 2017, pp. 163-179.

[19] C. B. Zoltowski, W. C. Oakes, and M. E. Cardella, "Students' Ways of Experiencing Human-Centered Design," Journal of Engineering Education, vol. 101, no. 1, pp. 28-59, Jan. 2012.

[20] P. H. Winne and R. Azevedo, "Metacognition," in The Cambridge handbook of the learning sciences, 2014, pp. 63-87.

[21] H. Vos and E. de Graaff, "Developing metacognition: a basis for active learning," European Journal of Engineering Education, vol. 29, no. 4, pp. 543-548, Dec. 2004.

[22] B. H. Chowdhury, "Learning to Learn - Concepts in a First Power Engineering Course," vol. 19, no. 1, pp. 31-39, 2004.

[23] A. I. Jack et al., "fMRI reveals reciprocal inhibition between social and physical cognitive domains," NeuroImage, vol. 66, pp. 385-401, Feb. 2013.

[24] E. A. Cech, "Culture of Disengagement in Engineering Education?," Science, Technology, \& Human Values, vol. 39, no. 1, pp. 42-72, Jan. 2014.

[25] G. Schraw, "Promoting general metacognitive awareness," Instructional Science, vol. 26, no. 1/2, pp. 113-125, 1998.

[26] S. D. Preston and F. B. M. de Waal, "Empathy: Its ultimate and proximate bases," Behavioral and Brain Sciences, vol. 25, no. 1, pp. 1-20, Dec. 2001.

[27] S. D. Preston and R. B. Stansfield, "I know how you feel: Task-irrelevant facial expressions are spontaneously processed at a semantic level," Cognitive, Affective and Behavioral Neuroscience, vol. 8, no. 1, pp. 54-64, Mar. 2008.

[28] R. Hughes, B. A. Tingle, D. B. Sawin, and D. B. Sawin, "Development of Empathic Understanding in Children," Child Development, vol. 52, no. 1, p. 122, Mar. 1981.

[29] C. Brems, D. K. Fromme, and M. E. Johnson, "Group Modification of Empathic Verbalizations and SelfDisclosure," The Journal of Social Psychology, vol. 132, no. 2, pp. 189-200, Apr. 1992.

[30] J. M. Spector, D. L. Christensen, A. V Sioutine, and D. McCormack, "Models and simulations for learning in complex domains: using causal loop diagrams for assessment and evaluation," Computers in Human Behavior, vol. 17, no. 5-6, pp. 517-545, Sep. 2001.

[31] Y. M. Goh, H. Brown, and J. Spickett, "Applying systems thinking concepts in the analysis of major incidents and safety culture," Safety Science, vol. 48, no. 3, pp. 302-309, Mar. 2010.

[32] J. Strobel, J. Hess, R. Pan, and C. A. Wachter Morris, "Empathy and care within engineering: qualitative perspectives from engineering faculty and practicing engineers," Engineering Studies, vol. 5, no. 2, pp. 137-159, Aug. 2013.

[33] J. Hess and N. Fila, "The Development and Growth of Empathy Among Engineering Students," in $A S E E$ Annual Conference \& Exposition, 2016. 
[34] S. Jordan, M. Lande, M. Cardella, and H. Ali, "Out of their world: Using alien-centered design for teaching empathy in undergraduate design courses," in 2013 IEEE Frontiers in Education Conference (FIE), 2013, pp. 907-913.

[35] E. Köppen and C. Meinel, "Empathy via Design Thinking: Creation of Sense and Knowledge," Springer, Cham, 2015, pp. 15-28.

[36] National Research Council, How people learn: Brain, mind, experience, and school: Expanded edition. National Academies Press, 2000.

[37] S. A. Ambrose, M. W. Bridges, M. DiPietro, M. C. Lovett, and M. K. Norman, How learning works: Seven research-based principles for smart teaching. John Wiley \& Sons, 2010.

[38] A. Young and J. Fry, "Metacognitive awareness and academic achievement in college students," Journal of the Scholarship of Teaching and Learning, vol. 8, no. 2, pp. 1-10, 2012.

[39] S. Y. McGuire, Teach students how to learn: Strategies you can incorporate into any course to improve student metacognition, study skills, and motivation. Sterling, VA: Stylus Publishing, 2015.

[40] C. A. Farrington et al., Teaching Adolescents to Become Learners: The Role of Noncognitive Factors in Shaping School Performance--A Critical Literature Review. The University of Chicago Consortium on Chicago School Research, 2012.

[41] E. Cook, E. Kennedy, and S. Y. McGuire, "Effect of Teaching Metacognitive Learning Strategies on Performance in General Chemistry Courses," Journal of Chemical Education, vol. 90, no. 8, pp. 961-967, Aug. 2013.

[42] D. S. Yeager and C. S. Dweck, "Mindsets That Promote Resilience: When Students Believe That Personal Characteristics Can Be Developed," Educational Psychologist, vol. 47, no. 4, pp. 302-314, Oct. 2012.

[43] T. Doyle and T. Zakrajsek, The new science of learning: How to learn in harmony with your brain. Sterling, VA: Stylus Publishing, 2013.

[44] J. Dunlosky, K. A. Rawson, E. J. Marsh, M. J. Nathan, and D. T. Willingham, "Improving Students' Learning With Effective Learning Techniques," Psychological Science in the Public Interest, vol. 14, no. 1, pp. 4-58, Jan. 2013.

[45] N. Zhao, J. G. Wardeska, S. Y. McGuire, and E. Cook, "Metacognition: An Effective Tool to Promote Success in College Science Learning.," Journal of
College Science Teaching, vol. 43, no. 4, pp. 48-54, 2014.

\section{APPENDIX A: TRANSDISCIPLINARY SKILLS SURVEY INSTRUMENT}

Please indicate how strongly you agree or disagree with each of the following statements.

$(5=$ Strongly agree, $4=$ Mildly agree, $3=$ Neither agree nor disagree, 2 = Mildly disagree, $1=$ Strongly disagree)

1. I prefer to deal with big picture and systems aspects rather than technical details.

2. I think I am good at project and personal organization skills.

3. I prefer leading teams rather than concentrating on my technical job.

4. It is important for me to learn from the differences between the expected and actual outcomes of action, and change my action to improve results.

Now thinking specifically of when you work on a team project or assignment, please indicate how strongly you agree or disagree with each of the following statements.

5. I value the contributions of other students to completing the whole task

6. I always consider interdependencies between project tasks, and how I might contribute to the project as a whole

7. I like to be proactive rather than just accept what has been decided by others

8. I work hard to maintain communication with others involved

9. I prefer to test the available alternative solutions and then recommend the best choice rather than to let others choose the preferred alternative

10. I think continuously about what can be improved rather than concentrating on my goal alone

11. I enjoy reviewing the whole project or assignment and giving feedback to my group

Please indicate how strongly you agree or disagree with each of the following.

12. I sometimes find it difficult to see things from another person's point of view.

13. I try to look at everybody's side of a disagreement before I make a decision.

14. I sometimes try to understand my friends better by imagining how things look from their perspective. 
15. If I'm sure I'm right about something, I don't waste much time listening to other people's arguments.

16. I believe that there are two sides to every question and try to look at them both.

17. When I'm upset at someone, I usually try to "put myself in their shoes" for a while.

18. Before criticizing somebody, I try to imagine how I would feel if I were in their place.

Please indicate whether you feel each of the following statement is true or false for you.

( 1 = True, $0=$ False)

19. I try to use learning strategies that have worked in the past.

20. I understand my intellectual strengths and weaknesses.

21. I know what kind of information is most important to learn.

22. I am good at organizing information.

23. I have a specific purpose for each learning strategy I use.

24. I learn best when I know something about the topic.

25. I know what the teacher expects me to learn.

26. I am good at remembering information.
27. I use different learning strategies depending on the situation.

28. I have control over how well I learn.

29. I can motivate myself to learn when I need to.

30. I am aware of what learning strategies I use when I study.

31. I use my intellectual strengths to compensate for my weaknesses.

32. I am a good judge of how well I understand something.

33. I find myself using helpful learning strategies automatically.

34. Select "false" on this line to show you are reading the prompts.

35. I know when each learning strategy I use will be most effective.

36. I learn more when I am interested in the topic.

Note: Question 34 is a validation question to screen out careless responses. Question 12 and Question 15 are reversely coded according to [5]. 